\title{
DANÇA CONTEMPORÂNEA: PERCEPÇÃO, CONŢRADIÇÃO E APROXIMAÇÃO
}

\author{
Paulo Henrique Alves de Souza
}

Centro de Educação Profissional em Artes Basileu França, Goiânia, Goiás, Brasil

\begin{abstract}
Resumo
O presente artigo tem como objetivo evidenciar qual a compreensão acerca da Dança Contemporânea que pessoas que estão envolvidas em processo de formação na área das Artes possuem. Ele apresenta uma análise a partir de uma investigação de campo, descritiva e de cunho qualitativo. Os sujeitos pesquisados foram alunos de um curso técnico em Dança Contemporânea da cidade de Goiânia. Ainda que as discussões acerca do que seja um movimento contemporâneo de dança sejam bastante amplas, tentamos a partir da análise de uma realidade, desvelar quais seriam os aspectos e características que pessoas envolvidas no processo de formação artística possuem a respeito de tal manifestação de dança. Alguns aspectos que foram encontrados se referem à multiplicidade, liberdade de criação, improvisação, pesquisa de movimento, compreensão crítica da realidade e rompimento com padrões estéticos.
\end{abstract}

Palavras-chave: Estética. Compreensão. Dança.

\section{Introdução}

$\mathrm{O}$

presente artigo tem como objetivo analisar as compreensões acerca da Dança Contemporânea que possuem os artistas da dança que estão se formando e que se formaram em um Curso Técnico em Dança Contemporânea. O enfoque desta pesquisa é uma análise específica de uma realidade e temos a pretensão de ampliar o conhecimento a respeito do tema tratado, pois percebemos que o campo de conhecimento de que trata esta pesquisa é um fenômeno que ainda está em discussão e que possui uma característica fundamental, a multiplicidade de opiniões.

A Arte é um fazer humano e desde muito cedo podemos perceber a necessidade que o homem tem de se expressar. Durante o processo de 
transformação que a sociedade foi passando ao longo dos anos, a dança em diferentes momentos históricos e sob influência de novas formas de organização social, assim como as Artes em geral, foi resignificando e construindo diferentes maneiras de se expressar e de se colocar no mundo.

A dança através dos tempos sofreu mudanças, transformando-se na sociedade atual em uma mistura cheia de cores, ritmos e estilos que ora guardam aspectos de danças mais antigas, ora surpreendem-nos com novas formas de expressão, concepção e criação de movimentos, além de lançar mão de diferentes maneiras de se apresentar, com propostas cada vez mais inusitadas.

Silva (2005), ao se referir a Arte Pós-moderna, que é o movimento que impulsiona as discussões em torno da Dança Contemporânea, relata que apesar dos diferentes pensamentos em relação a quando surgiu tal movimento, alguns aspectos são comuns na fala dos diversos autores que tratam do tema, que no caso são o da pluralidade estética, fragmentação e justaposição de imagens, experimentação exaustiva, ousadia em ironizar o modus vivvendi, entre outros (SILVA, 2005).

Neste trabalho priorizamos tratar com maior atenção o período Pós-Moderno nas Artes, já que a Dança Contemporânea que é o ambiente de discussões deste artigo está historicamente situada neste período. Ressaltamos que as discussões acerca do que seja realmente um período Pós-Moderno na história são bastante numerosas. Existem autores que defendem a prerrogativa de que o momento atual que estamos vivendo é de fato um período com característica de pós-modernidade, porém há também pesquisadores que contrapõem esse pensamento, com a argumentação de que o período Pós-Moderno nas Artes ainda está por acontecer.

Não obstante a tal pluralidade de pensamentos e conceitos sobre o que seja a Arte Pós-Moderna, a Dança Contemporânea por surgir a partir deste contexto também carrega dificuldades em relação à sua definição. Silva (2005) diz que este debate tanto nas Artes quanto na dança contemporânea propriamente dita são oriundos de análises que estão sujeitas a constantes modificações, pois a discussão acerca dos temas surge ainda no momento em que acontece e é definido o fenômeno.

O cenário atual das discussões acerca do que seja a Dança Contemporânea e o próprio movimento Pós-Moderno nas Artes é terreno fértil para se pensar novas possibilidades de construção tanto teórica 
quanto artística, pois se referem ao período em que a sociedade se encontra. A cada nova discussão que surge, diferentes questionamentos e caminhos para se pensar esses temas se fazem necessários, para que se consiga ao menos definir quais são as suas características ao invés de tentar uma definição fechada e estática de um fenômeno que se propõe a ser um processo dinâmico e que está em constante transformação.

Nesse sentido, este trabalho que se caracteriza por ser uma pesquisa de campo que desenvolveu-se a partir de um enfoque descritivo e qualitativo para análise dos dados, tem por objetivo investigar qual a compreensão em relação ao conceito e características da Dança Contemporânea que os alunos de um curso técnico em Dança Contemporânea de Goiânia possuem. A partir do que estes sujeitos apontam como sendo aspectos/características de tal forma de Arte pretende-se evidenciar os diferentes olhares e possibilidades de se pensar em um movimento contemporâneo na dança e como ele é identificado e compreendido por esses indivíduos.

No total foram pesquisados 14 alunos do referido curso, sendo que todos assinaram um termo de consentimento livre e esclarecido para participar da pesquisa e assegurar a utilização dos dados obtidos pelo pesquisador. Para a coleta de dados foi utilizado um questionário com perguntas abertas, de modo que os membros participantes deveriam respondê-lo no ato da entrega, sem delimitação de tempo, sob a supervisão do pesquisador e sem sofrer interferências do mesmo ou de terceiros.

A análise dos dados obtidos na pesquisa ocorreu de forma que os mesmos fossem discutidos e confrontados com um referencial teórico de autores que dialogam com o tema proposto. Nesse sentido foi elaborada ao final do trabalho uma síntese das principais características obtidas através da análise dos dados, procurando dar um parâmetro geral de como é a percepção/compreensão acerca da Dança Contemporânea dos alunos pesquisados.

\section{História e sentidos de uma dança revolucionária}

Para tratar do termo Dança Contemporânea faz-se necessário uma breve caminhada ao passado para que possamos identificar alguns aspectos de tal movimento desde suas primeiras especulações na sociedade. 
Chamo de especulações e não aparições da Dança Contemporânea as primeiras formas de se pensar e produzir dança que surgiram logo após o auge do movimento da Dança Moderna. Utilizo o termo especulações, por entender sê-lo mais conveniente ao se tratar de um tema que ainda é discutido e pensado atualmente, o pós-modernismo na Arte. Especular está intimamente ligado ao ato de transitoriedade/transformação que a Dança Contemporânea vem passando ao longo dos anos. Desde o início ela esteve ligada a diferentes propósitos estéticos, o que historicamente produziu uma série de diferenças na nas suas características e que acabava por colocar em cheque o que vinha sendo produzido nas diferentes épocas da humanidade em relação à Dança.

A Dança Moderna historicamente foi o movimento que respectivamente rompeu com padrões estéticos de uma época voltada para a Dança Clássica e antecedeu as discussões em relação às propostas contemporâneas de dança.

Para que possamos entender como se consolidou o movimento da Dança Moderna, primeiramente é necessário entender que a mesma foi consolidada a partir de alguns princípios fundamentais. Um tanto quanto curioso para nos referirmos à história da Dança Moderna é dizer que um dos primeiros a conceber ideais, princípios e pensamentos acerca do que mais tarde iria consolidar tal movimento de dança foi um músico: François Delsarte.

Delsarte influenciou praticamente todos os precursores que consolidaram a Dança Moderna. Seus princípios além de influenciarem pensadores da dança também influenciaram atores, oradores e artistas em geral. Para ilustrar como as ideias de Delsarte recaem sobre a dança Bourcier (2001) elenca algumas consequências dos pensamentos deste músico em relação á dança, como: a utilização de todo o corpo em função da expressão com ênfase no torso; a concepção de que através da contração e do relaxamento dos músculos é que se obtém a expressão; a ideia de que os sentimentos se traduzem corporalmente sendo que os gestos os reforçam, assim como o inverso também ocorre.

O grande trunfo da Dança Moderna foi o rompimento que seus precursores e fundadores causaram em relação à estética clássica do final do século XIX. Cabe ressaltar que esse rompimento foi pequeno na medida em que praticamente todas as técnicas de Dança Moderna que foram elaboradas e sistematizadas utilizavam ainda muitos dos 
movimentos provenientes do Ballet Clássico. Em contrapartida, a filosofia e concepção de mundo dos precursores e fundadores da Dança Moderna foram extremamente categóricas em romper com a hegemonia da Dança Clássica da época, a qual se prendia em histórias narrativas e que possuíam uma temática ligada às paixões profundas ilustradas geralmente por seres etéreos.

Mais tarde com o surgimento de novos revolucionários no mundo da dança, aos poucos o rompimento com padrões estéticos vai se tornando cada vez maior e mais concreto, e acaba por subsidiar as primeiras discussões do que viria a ser considerado o movimento da Dança Contemporânea.

Podemos perceber que inicialmente a Dança Contemporânea surgiu em um período de revolução e resignificação das formas de se conceber a dança na sociedade. Entender que os fatos históricos não sugerem evoluções ou involuções é primordial para se admitir os pressupostos de um movimento contemporâneo na dança, já que o mesmo está em constante transformação.

Apesar de os livros de história da dança em sua maioria nos apresentar uma ilustração linear da trajetória da dança nos períodos históricos, devemos ressaltar que as transformações nas concepções estéticas de se pensar e produzir a Dança ou a Arte em geral são um contínuo processo dialético de afirmações e reafirmações, pois nenhum movimento artístico exclui o outro, já que todos estão presentes nas sociedades até hoje. "Esses ciclos evolutivos e históricos crescem em forma de espiral, não havendo quebras e rompimentos abruptos, mas sim lentas transformações processuais." (JOSÉ, 2011, p. 3).

Garaudy (1980) chama de "Nova Dança" o movimento que surgiu a partir de Alwin Nikolais e Merce Cunningham, os quais se propunham a contrapor os fins e meios da Dança Moderna. O termo é designado em analogia a outros movimentos de Arte, como o do Novo Romance, Novo Teatro e Novo Cinema, todos advindos do pós-modernismo. Podemos notar que o que Garaudy chama de Nova Dança são de fato as primeiras ideias e pressupostos da Dança Contemporânea.

O autor ressalta que nas décadas de 50 e 60 , o movimento da Nova Dança surgiu em contraposição principalmente da expressão dramática das emoções e das paixões que advinham da Dança Moderna. Os novos pensadores da Dança não queriam mais estar presos à indiferença do Balé Clássico em relação às paixões profundas e à história, 
além de não aceitar o código imutável de movimentos que a Dança Clássica tinha como característica principal. Também não poderiam mais aceitar o propósito da Dança Moderna em viver intensamente o que há de mais significativo nas promessas e nas angústias do mundo moderno (GARAUDAY, 1980).

A necessidade em celebrar o movimento começou a surgir, ou seja, a Dança não precisava mais ter um significado, sentimento, emoção ou qualquer motivação inicial que não seja o movimento para que possa acontecer. Merce Cunninghan (s.d., n .p. apud BANES, 1980, p. 6, tradução nossa) ao dizer que "a dança pode ser sobre qualquer coisa, mas é fundamentalmente e primeiramente sobre o corpo humano e seus movimentos..." deixa essa ideia bem clara. Percebemos que a Dança Contemporânea começava a contrapor as formas de organização e expressão das outras estéticas de dança, pois abre mão do sentimento, narração, estrutura linear e outros aspectos característicos da Dança Clássica e Moderna. Começava então a eclodir uma nova forma de se pensar e conceber dança.

Outra característica da Dança Contemporânea em suas primeiras especulações se refere ao que Merce Cunninghan trouxe como conceitos e questionamentos a partir de um novo olhar sobre a dança, no qual a narrativa dava lugar à estrutura fragmentada, o abandono do palco convencional dava lugar ao uso de diferentes e inusitadas opções cênicas, o processo de criação a partir da experimentação e improvisação era utilizado intensamente e a independência entre música, figurino, cenário, iluminação e dança começava a surgir. A partir destes ideais podemos pressupor que a dança deixava seu objetivo principal de ilustrar propostas e passava a lidar com a proposição e composição de ideias (SILVA, 2005).

$\mathrm{O}$ abandono da narrativa para dar lugar à estrutura fragmentada talvez seja um dos fatores mais adequados aos artistas que propõem trabalhos a partir de estética contemporânea de dança, pois não há mais a necessidade em se contar histórias ou se criarem estórias e sim a preocupação em questionar e propor ideias. $\mathrm{O}$ abandono do palco como estrutura fundamental se refere à contraposição em relação à espetacularização da dança, ou seja, as ruas, estacionamentos, lugares abertos ou fechados, no meio do povo ou em qualquer lugar que vá servir ao propósito de quem está dançando pode ser utilizado como espaço cênico. 
A não padronização de corpos é outro fator marcante que a Dança Contemporânea guarda em sua trajetória. Diferentemente do Balé Clássico e até mesmo da Dança Moderna que pregavam como belo um corpo longilíneo e alongado, a dança contemporânea principalmente na década de 60 começou as ser praticada por pessoas sem essas características e que não possuíam nenhuma formação em dança.

Podemos dizer então que a Dança Contemporânea passou por um período de democratização, pois abolia-se pré-conceitos de estruturas físicas e até de movimentos pré-estabelecidos, "[...] no limite, qualquer um podia ser bailarino, e a dança deixava de atrelar-se a uma escola para pertencer ao corpo de quem estivesse se movimentando." (STUART, 1999, p. 199).

Atualmente ainda muito se discute sobre o que de fato seja a Dança Contemporânea. Nesse sentido vale citar Ana Maria de São José, professora e pesquisadora do curso de Dança da Universidade Federal de Sergipe, que ao ser questionada em seu cotidiano em relação a produzir um conceito acerca do tema, sabiamente responde:

[...] não existe apenas um conceito que possa dar conta da complexidade da dança contemporânea, não existe apenas um caminho para se pensar a dança que é realizada na contemporaneidade, não existe apenas uma dança contemporânea por se tratar de construções coreográficas diversas, provenientes de lugares e culturas diferenciadas, etc. Assim o tema dança contemporânea sempre gera discussões, dúvidas, conflitos e questionamentos (JOSÉ, 2011, p. 2-3).

A partir da fala da autora podemos evidenciar que ao se falar em Dança Contemporânea devemos ter o cuidado de não estar fixando conceitos e teorias absolutas acerca de um tema que reserva em sua magnitude uma gama enorme de possibilidades que estão ligadas a diferentes propósitos estéticos, artísticos e filosóficos, que são criados e recriados à luz de épocas e culturas diferentes.

Snizek (2007) vem colaborar com tais pressupostos quando diz que a Dança Contemporânea se caracteriza por produzir uma "corporalidade" única, metafórica, e que pressupõe um isolamento em unidades menores de percepção os elementos do gesto e do corpo. A autora ainda ressalta que a pesquisa, observação, inquirição, reflexão, experimentação e expressão passam da categoria de recursos para se pro- 
duzir dança, para a categoria de objetivos da dança, ou seja, a Dança Contemporânea está intimamente ligada à transitoriedade e multiplicidade de propostas que surgem a partir de processos cada vez mais complexos para se pensar e produzir dança.

Podemos perceber que a Dança Contemporânea não se concretiza como uma técnica, entendemos que a partir das reflexões geradas por vários autores, a Dança Contemporânea é mais uma forma de se pensar a dança a partir de diferentes poéticas do que uma técnica restrita. Colaborando com essa ideia e a partir de pressupostos distintos podemos citar alguns autores que apesar de contribuições pontuais e distintas em alguns pontos, colaboram com a ideia de que a Dança Contemporânea não é uma técnica, mas sim uma forma de se pensar a dança. Dentre estes autores citamos Agambem (2009) apud José (2011), Cauquelin, (2005), Gadelha (2010), Gil (2001), Pavlova (2002), Siqueira (2006), Tomazzoni (2006) e José (2011).

Louppe (2000) em seu artigo "Corpos Híbridos" vai tratar do pressuposto de que esse hibridismo cultural que a Dança Contemporânea carrega em si não se refere a uma polissemia, mas sim em uma forma particular de buscar em diferentes corporeidades incompatíveis, díspares, e às vezes contraditórias, elementos para a criação de uma diversidade artística tão imensa que ultrapassa a imaginação até mesmo de quem está no centro do processo de criação de uma proposta contemporânea de dança. Notamos aqui a abrangência que a Dança Contemporânea atinge em relação às outras manifestações de dança no que se refere à condição de exigir padrões de corpos e movimentos, já que a partir dos pressupostos deste movimento contemporâneo da dança pode-se abrir mão do bailarino formal enquanto o único sujeito dançante, como ainda acontecia no Balé Clássico e na Dança Moderna.

Para ilustrar ainda mais essa multiplicidade de caminhos que a Dança Contemporânea se resguarda, ainda vale expor o fato de que o bailarino contemporâneo não se limita ao aprendizado de uma técnica de referência, pois desde o surgimento de novos pensadores a partir da estética da Dança Moderna, pode-se perceber que a pulverização de saberes, técnicas, e quem sabe até de uma Cultura Coreográfica ${ }^{1}$, é o

1- A autora utiliza o termo se baseando em Dena Davis, que em seu artigo "Le corps ecletique", onde diz que as obras atuais em Dança Contemporânea são muito pontuais, produzidas pela precipitação inesperada de múltiplos elementos. A autora ainda define que esta cultura está intimamente ligada à moda do momento, e que varia de acordo com a mesma. 
que se constitui como vivência para os atuais bailarinos (LIMA, 2003).

A partir do que já foi dito até aqui, pretende-se agora fazer uma análise qualitativa dos dados que foram obtidos através dos questionários aplicados aos sujeitos que foram pesquisados, para que se possa evidenciar o que esses indivíduos compreendem em relação à Dança Contemporânea.

\section{Múltiplas percepções de olhares... Em várias dimensões?!}

Faz-se necessário antes de partir para a análise das respostas obtidas através do questionário proposto para esta pesquisa, saber quais as indagações que foram colocadas para os indivíduos que colaboraram com este estudo. No intuito de que os sujeitos pesquisados pudessem exprimir quais as características, percepções, olhares e inquietações acerca da Dança Contemporânea que os mesmos possuem, foram utilizadas duas questões, sendo que a primeira era: "Por que você escolheu fazer Dança Contemporânea?" e a segunda: "Para você, qual ou quais são as características que diferenciam a Dança Contemporânea das outras manifestações de Dança?”.

As questões foram elaboradas para que a partir das respostas obtidas pudéssemos identificar na opinião dos sujeitos pesquisados algumas categorias que os mesmos identificam como próprias de um movimento contemporâneo na dança. Acreditamos que ao serem questionados acerca de sua escolha em relação à Dança Contemporânea seria possível evidenciar aspectos em relação a como esta manifestação de dança era percebida por esses indivíduos antes mesmo de estarem envolvidos em um processo de pesquisa e formação em Dança Contemporânea.

$\mathrm{Na}$ maioria das respostas obtidas percebeu-se a relação entre a liberdade de expressão, das múltiplas possibilidades de criação, da descoberta de novas formas de se movimentar, que os alunos vinculavam à Dança Contemporânea. Sendo assim evidenciamos as seguintes respostas: "[...] é a descoberta de diversas técnicas, estilos, movimentações e criações permitindo que o próprio intérprete internalize cada sensação e movimento do seu corpo. [...]" (Entrevistado 13); “[...] não existe um caminho ditado, há sempre uma nova escolha, uma nova descoberta, o corpo usado enquanto pensamento. [...]" (Entrevistado 14); “[...] Para mim, a dança contemporânea me permite seguir vários 
caminhos sem me prender em apenas um estilo de movimentação. [...]" (Entrevistado 3).

[...] A dança contemporânea se expressa por uma linguagem que reflete liberdade de composição, diferença de personagem e enredo. Mas ela, principalmente tem como poéticas uma linguagem ampla e independente de um roteiro. (Entrevistado 11).

Nesse sentido e para que possamos perceber a relação da fala dos alunos pesquisados com a de pesquisadores da Dança Contemporânea, trazemos Silva (2005) que diz que a dança dos nossos dias de certa forma pode ser classificada como aquela que admite a estética da liberdade, no sentido de possuir inúmeras formas de se expressar, pensar e produzir dança. A autora utiliza as palavras de Elizabeth Dempster ao afirmar que o corpo na Dança Contemporânea está disponível para muitos discursos, sendo que ocorre então um direcionamento de um olhar específico e único para o processo de construção de inúmeros corpos. Na medida em que se pode entender essa dança como uma "escritura" do corpo, pode-se afirmar que ela é condicional, circunstancial e prioritariamente transitória, pois é uma escritura que se apaga no mesmo momento em que é escrita.

Ana Carolina Mendes (2011), pesquisadora e professora do curso de Licenciatura em Dança do Instituto Federal de Brasília em sua obra "Dança Contemporânea e o movimento tecnologicamente contaminado" (2011) também vem dialogar a partir destes pressupostos, quando ao falar da Dança Contemporânea em sua multiplicidade de caminhos diz o seguinte:

Em meio a uma superabundância de informações, a dança contemporânea pode ser feita de múltiplos, de bulbos que, como os pontos de organização dentro do caos, estruturam-se singularmente, navegando entre as nuanças do que foi anteriormente posto em termos de modelos dicotomizados. [...] É por isso que se pode ter Pina Bausch e sua dança-teatro; o Butoh japonês; o Grupo Corpo e sua unidade entre movimento, música, cenário e figurino; Débora Colker e sua dança de extremo rigor físico [...] e os que se intitulam fazedores de dança-tecnologia. [...] Todos coexistindo no espaço-tempo do hoje. Se algo pode ser identificado como marca da dança, contemporaneamente, esse algo é a 
diversidade, é a possibilidade de tudo incluir, tudo falar, de a nada se opor e assim se opor a tudo, pois nessa abertura todos os modelos e padrões inscreve-se o próprio questionamento modelar e do padronizar, transformando-os, portanto (MENDES, 2011, p. 68,69).

Podemos perceber que atualmente os olhares acerca das produções contemporâneas em dança se refletem em uma perspectiva de perceber como elas se organizam, e não mais no que elas querem dizer, ou seja, em meio a esta multiplicidade de poéticas e formas de se conceber a Dança Contemporânea, o olhar de quem assiste não está mais voltado para o sentido e o que quer dizer cada proposta, mas sim para as formas de organização cênica e artística particulares de cada nova produção.

Wachowichz (2008) ressalta que há uma multiplicidade de proposições da Dança Contemporânea, e a mesma está ligada ás suas estruturas de organização das ideias, ou seja, as obras são contaminadas de olhares múltiplos e percepções estéticas de diferentes indivíduos, o que mais uma vez vem colaborar com o pressuposto de que ao se pensar em um movimento contemporâneo da dança é preciso admitir a transitoriedade e multiplicidade de ideais presentes neste fenômeno.

Outro fator que merece destaque nas respostas obtidas no questionamento se refere à utilização pela dança contemporânea de referenciais advindos de outras épocas e de releituras de técnicas de dança, o que confere possibilidades de criação e de composição artística inimagináveis na cena contemporânea. Nesta perspectiva ainda encontramos as seguintes falas: "[...] a dança contemporânea te permite criar, a medida que desenvolve habilidades técnicas que te desafiam a superação, te permite ir e vir na história, proporcionando um pensamento crítico de cada época, do meio e da sociedade. [...]" (Entevistado 12).

Percebemos na fala do entrevistado 12 que o mesmo possui uma ideia equivocada em relação á Dança Contemporânea, quando o mesmo diz que ela desenvolve habilidades técnicas. Como já foi dito anteriormente a partir da utilização dos referencia teóricos, a Dança Contemporânea não se atenta a desenvolver e consolidar uma técnica ou habilidades técnicas, ela está mais ligada a uma forma de se pensar a dança a partir de várias poéticas.

“[...] A Dança Contemporânea se caracteriza principalmente pelo rompimento com as tradicionais manifestações da dança, como Ballet 
e Jazz. Ela evidencia uma nova visão de mundo, uma releitura de conceitos pré-estabelecidos e também está em constante movimento. [...]" (Entrevistado 10).

[...] Possibilidade de utilização de som e silêncio, diferentes percepções e certas propriedades de movimento, técnicas/estilos isolados ou combinados, espaços cênicos diversos, for$\mathrm{ma} /$ conteúdo articulados às ideias dos coreógrafos, uso da poética racional e ao mesmo tempo passando pelo sensível; [...] (Entrevistado 9).

Em relação às respostas acima mencionadas, cabe ressaltar que novamente pode-se perceber presente nas falas dos alunos a temática da multiplicidade de caminhos que a Dança Contemporânea possui. Gostaria ainda de destacar a fala do entrevistado número 9, quando diz que ela se propõe à: "[...] discussão de questões da atualidade, dialogando com questões de um passado não tão distante [...]". Também nota-se o mesmo pressuposto na fala do entrevistado número 10:

Escolhi a Dança Contemporânea porque ela propicia uma maior compreensão da linguagem artística que nos cerca e do mundo no âmbito geral. Dentro da sua gama de possibilidades, ela nos proporciona vivenciar sensações, sentimentos e movimentos capazes de romper com a barreira do real, sem deixar os questionamentos relativos à nossa sociedade (Entrevistado $10)$.

Percebemos que além do aspecto da multiplicidade, obtivemos respostas que nos mostram que os questionamentos relativos à sociedade também são características de um movimento contemporâneo na dança, além de proporcionar uma vivência de sensações e sentimentos de certa forma surreais, pois ultrapassam o simples fato de decorar e repetir sequências de movimentos, estimulando o contínuo exercício da reflexão e criação. Podemos evidenciar isso nos momentos de experimentação exaustiva e improvisação, que é quando cada um irá a partir de sua esfera de conhecimento em relação ou não com o outro, descobrir caminhos ainda não trilhados e novas possibilidades de se movimentar e por consequência modificará sua relação com o seu corpo e quem sabe até com a dança a partir destas experiências. 
Gil (2001) se refere a essas experiências que a Dança Contemporânea proporciona a quem está envolvido em um processo artístico. O autor ressalta que tanto quem está no referido ato de dançar, quanto quem está apreciando um trabalho em Dança Contemporânea não se restringe a apenas dançar ou observar, mas ambos criam um jogo de significados que não podem ser traduzidos apenas com palavras para descrever movimentos e uma lógica factual para descobrir o nexo do que está sendo exposto. $\mathrm{O}$ autor ressalta que o fato de não compreendermos a dança se dá pelo simples fato de que ela não é feita para ser compreendida, pois ao apreciarmos um trabalho em Dança Contemporânea ao invés de apenas observar o que se passa no ambiente cênico, recebemos o movimento dançado com nosso corpo inteiro, captando a sucessão abstrata e contínua em relação ao movimento e às diferenças das formas.

Ainda buscando evidenciar as características de um movimento contemporâneo de dança segundo os sujeitos pesquisados, encontramos em algumas respostas a presença do pensamento ligado à contínua ação de reflexão a partir do processo de pesquisa/experimentação, além de ressaltar a diversidade de temas que a Dança Contemporâneo sugere. "[...] A principal característica que a diferencia das outras estéticas de dança é a relação do desvelamento, da experimentação, da não cristalização de pensamentos [...]" (Entrevistado 13); “[...] Pela estética que não liga tanto para a perfeição dos movimentos, valorizando somente o que é bonito. A liberdade de temas. $\mathrm{O}$ estudo do corpo. A dialética e a didática [...]." (Entrevistado 2).

Um aspecto marcante do movimento da Dança Contemporânea que não esteve presente em nenhuma das falas dos entrevistados se refere à utilização de outras formas de Arte em construções contemporâneas de dança. Para confirmar esse aspecto em relação ao movimento contemporâneo da dança novamente citamos a pesquisadora Ana Maria de São José que ao se referir particularmente a essa característica ressalta que:

Embora a inter-relação entre as artes tenha ocorrido também em épocas anteriores, a dança contemporânea abre possibilidades para as múltiplas formas inter, multi e transdiciplinares, na relação, interação e diálogo com outras expressões artísticas, tais como o teatro, artes plásticas, performance, literatura, cinema, 
música e tecnologia, estabelecendo diferentes diálogos criativos e fusões estéticas coreográficas. (JOSÉ, 2011, p. 9)

Como relata a autora, mesmo este entrecruzamento da dança com outras formas de Arte já ter sido observado em outras épocas, é no advento da Dança Contemporânea que a resignificação destas interelações são mais fortes, pois o diálogo criado para gerar um ambiente de conexão entre o que é dança, teatro, pintura, cinema, música e etc. acontece de forma mais sutil, o que acaba por vezes dificultando a diferenciação do que seja um espetáculo, performance ou coreografia de Dança Contemporânea com contribuições de outras fontes artísticas de por exemplo de uma obra teatral com pequenos insights de dança em seu enredo.

Através da análise das respostas obtidas podemos perceber a diversidade de olhares e percepções que os sujeitos pesquisados têm a respeito da Dança Contemporânea. A maioria dos indivíduos, mesmo que de forma diferente, associam a liberdade de criação e multiplicidade de caminhos ao processo criativo em Dança Contemporânea.

\section{Considerações finais}

Como já mencionamos anteriormente, não havia a pretensão de se criar um conceito em relação à Dança Contemporânea a partir deste estudo, mas sim de evidenciar como sujeitos que estão diretamente ligados ao processo artístico, mesmo que em formação, percebem e enxergam como características e aspectos que podem dar indicação do que seja um movimento contemporâneo de dança.

Verificamos que os aspectos ligados às múltiplas possibilidades de criação, improvisação, pesquisa de movimento, rompimento de padrões e estéticas, diversidade de pensamentos e compreensão crítica em relação ao mundo são características citadas pelos sujeitos pesquisados.

Identificamos que os aspectos citados pelos sujeitos que participaram deste estudo são evidenciados nas falas de vários autores que tratam do tema. Não foram encontrados grandes conflitos em relação a como os indivíduos percebem a Dança Contemporânea, pois as respostas dos entrevistados em geral se completavam, sendo que às vezes se referiam aos mesmos pressupostos, porém com palavras e frases diferentes. 
Percebemos que se faz necessário que os estudos científicos em relação à Dança Contemporânea sejam ampliados, para que possamos cada vez mais perceber o quanto esse tema é terreno fértil para gerar discussões e questionamentos acerca da diversidade de pensamentos em relação a esta manifestação artística que vem se transformando e resignificando seus aspectos ao longo dos tempos.

\title{
CONTEMPORARY DANCE: PERCEPTION, CONTRADICTION AND AP- PROACH
}

\begin{abstract}
This article aims to highlight which the understanding about the concept and characteristics of contemporary dance that people who are involved in the process of training in the area of the arts they have. He presents an analysis from a research field, descriptive and qualitative. The studied subjects were students of a technical course in Contemporary Dance of the city of Goiania. Yet that the discussions about what is a contemporary movement of dance are pretty large, we tried from the analysis of reality, unveil what would be the aspects and characteristics that people involved in the process of artistic training have the respect of such a manifestation of dance. Some aspects that were found relate to multiplicity, freedom of creation, improvisation, movement research, critical understanding of reality and bursting with aesthetic standards.

Keywords: Esthetics. Comprehension. Contemporary Dance.

\section{DANZA CONTEMPORÁNEA: PERCEPCIÓN, ENFOQUE E CONTRA- DICCIÓN}

\section{Resumen}

En este artículo se pretende mostrar que la concepción de la danza contemporánea que las personas que están involucradas en el proceso de formación en las artes tienen. Se presenta un análisis de una investigación de campo, descriptivo y cualitativo. Los sujetos de estudio fueron alumnos de un curso técnico en Danza Contemporánea en Goiânia. Aunque las discusiones sobre lo que es un movimiento contemporáneo de la danza son bastante grandes, tratamos a partir del análisis de una realidad, revelando cuáles son los rasgos y características que las personas involucradas en el proceso de formación artística tenga con respecto a tales expresiones de la danza. Algunos aspectos que se han encontrado se refieren a la multiplicidad, libertad creativa, improvisación, movimiento investigación, la comprensión crítica de la realidad y romper con las normas estéticas.

Palabras clave: Estética. Comprensión. Danza Contemporánea.

Pensar a Prática, Goiânia, v. 16, n. 4, p. 956-1270, out./dez. 2013 


\section{Referências}

BANES, S. Terspsichore in sneakers. Boston: Houghton Mifflin Company, 1980.

BOURCIER, P. História da Dança no Ocidente. 2. ed., São Paulo: Martins Fontes, 2001.

CAUQUELIN, A. Arte contemporânea: uma introdução. São Paulo: Martins Fontes, 2005.

GADELHA, R. C. P. Corpografias em dança contemporânea. 2010. 347 f. Tese (Doutorado em Sociologia)-Programa de Pós- Graduação em Sociologia, Universidade Federal do Ceará, Fortaleza, 2010.

GARAUDY, R. Dançar a vida. Rio de Janeiro: Nova Fronteira, 1980.

GIL, J. Movimento total: o corpo e a dança. Lisboa: Relógio D’Água, 2001.

HASS, A. N. et al. A percepção do bailarino de dança contemporânea sobre "ser bailarino". Revista Cena, Porto Alegre, n. 9, 2011.

JOSÉ, A. M. de S. Dança Contemporânea: um conceito possível? In: COLÓQUIO INTERNACIONAL "EDUCAÇÃO E CONTEMPORANEIDADE", 5., 2011, São Cristovão, SE. Anais... São Cristovão, SE: UFS, 2011.

LIMA, D. Corpos humanos não identificados: hibridismo cultural. In: PEREIRA, R.; SOTER, S. (Orgs.). Lições de dança 4. Rio de Janeiro: UniverCidade Editora, 2003. p. 81-108

LOUPPE, L. Corpos híbridos. IN: SOTER, S.; PEREIRA, R. (Orgs). Lições de Dança 2. Rio de Janeiro: UniverCidade Editora, 2000. p. 27-40.

MENDES, A. C. de S.S.D. Dança Contemporânea e o movimento tecnologicamente contaminado. Brasília: Editora IFB, 2011.

PAVLOVA, A. Deu a louca no coreógrafo. Jornal O Globo, Rio de Janeiro: 1/11/ 2002. 
SILVA, E. R. Dança e pós-modernidade. Salvador: EDUFBA, 2005.

SIQUEIRA, D. C. O. Corpo, comunicação e cultura: a dança contemporânea em cena. Campinas: Autores Associados, 2006.

SNIZEK, A. B. A dança contemporânea carioca dos anos 1990: corpo, política e comunicação. Contemporânea, Rio de Janeiro, v. 5. n. 1, p. 109-118, 2007.

STUART, I. A experiência do Judson Dance Theather. IN: PEREIRA, R.; SOTER, S. (Orgs.). Lições de Dança 1. Rio de Janeiro: UniverCidade Editora, 1999. p. 191-204.

TOMAZZONI, A. Essa tal dança contemporânea. 2006. Disponível em <http://idanca.net/esta-tal-de-danca-contemporanea/> Acesso em 20 fev.2012.

WACHOWICZ, F. Organismo Dança Contemporânea. IN: XAVIER, J.; MEYER, S.; TORRES, V. (Orgs). Coleção Dança Cênica: Pesquisas em Dança. Joiville: Letradágua, 2008. p.110-131.

Recebido em: 21/09/2012

Revisado em: $12 / 11 / 2012$

Aprovado em: 25/02/2013

Endereço para correspondência

phalves_89@hotmail.com

Paulo Henrique Alves de Souza

Centro de Educação Profissional em Artes Basileu França

Av Universitária, 1750

Setor Leste Universitário - Goiânia , GO - 74605-010 